\title{
Representação das religiões de matriz africana na CDD: uma análise crítica da Umbanda no Brasil
}

Representació de las religiones de influencia africana en la CDD: un análisis crítico de la Umbanda en Brasil Representation of religions of African influence in CDD: a critical analysis of Umbanda in Brazil

Marcio Ferreira da SILVA, Carlos Cândido de ALmEIDA

Departamento de Ciência da Informação, Faculdade de Filosofia e Ciências, Universidade Estadual Paulista - UNESP Marília, SP, Brasil, soimers@gmail.com, carlosalmeida@marilia.unesp.br

\section{Resumen}

Se discute la cuestión de la representación de la religión brasileña Umbanda a partir de un análisis crítico que se sustenta en la Teoría de las Representaciones Sociales. Se considera que los sistemas de clasificación universal, como la CDD, no representan adecuadamente esta religión debido a su complejidad no acogida por el sistema. De este modo, se pueden reforzar desigualdades, intolerancia religiosa y, sobre todo, el racismo estructural debido a una representación errónea que imposibilite el acceso al conocimiento sobre la Umbanda.

Palabras clave: Organización del conocimiento. Representación del negro. Sistemas de clasificación. Identidad afrobrasileña. Clasificación Decimal de Dewey. Umbanda. Brasil.

\section{Introdução}

A visão homogeneizante de cultura tem, na contemporaneidade, explicações nos processos que envolvem a globalização. Hall (2001) destaca que o ponto estratégico global de ampliação dos mercados e do consumismo, configurado no processo de globalização, está ancorado na crescente expansão da homogeneização das culturas.

Movimentos contra a homogeneização sugerem o contrário, uma vez que a ação de uniformização ou homogeneização cultural encontrou resistência. Sobretudo, observa-se a reunião e composição de fenômenos contemporâneos em movimentos organizados, denominados coletivos, o que se configura como uma nova característica de resistência cultural local e de representação da realidade.

As mudanças decorrentes na trama social reuniram esforços protagonizados por novos grupos sociais, acompanhadas de exigências à participação efetiva institucional e, sobretudo, fizeram entrever novas discussões sobre os processos de representação. Um aspecto indutor desse agrupamento encontra ambiente fértil na questão da identidade conforme abordada, por exemplo, na

\begin{abstract}
The representation of the Brazilian Umbanda religion is discussed from the point of view of the Theory of Social Representations. It is considered that Universal Classification Systems, such as the CDD, do not adequately represent this religion because its complexity is not welcomed by the system. Because of this, it can reinforce inequalities, religious intolerance and, above all, structural racism due to a misrepresentation that precludes access to knowledge on Umbanda.
\end{abstract}

Keywords: Knowledge Organization. Representation of black people. Classification Systems. Afro-Brazilian identity. Dewey Decimal Classification. Umbanda. Brazil.

perspectiva de estudantes, mulheres, grupos étnicos, religiosos, ecológicos, pacifistas (Santos, 1999, p.40).

O discurso e as escolhas que representavam a memória e suas histórias tiveram como ponto de partida uma visão deslocada acerca dos conteúdos que refletiam, sobretudo, os aspectos identitários desses grupos a partir de uma representação "sobre". O contexto das trocas e contatos, da produção de conteúdo das narrativas e compartiIhamentos das identidades, a cultura, os saberes milenares e as práticas religiosas são desconsideradas, porque seu surgimento fazia parte do senso comum. Ao não se sentirem representados, os sujeitos sociais interagem e reivindicam o papel de estabelecer um processo de autoafirmação e fortalecimento das identidades.

O protagonismo de ação desses grupos tem provocado reflexões no campo científico e erigido reivindicações no contexto do ambiente acadêmico e institucional. Alinhando-se a essas reflexões, nesta pesquisa, abordaremos o aspecto relevante da representação do negro nos sistemas de organização do conhecimento, sistemas de classificação do conhecimento que permitem organizar documentos e informação. São, pois, estruturas que obedecem a uma ordem lógica com 
a utilização de códigos numéricos, alfabéticos ou mistos (Barité, 2013), como, por exemplo, a Classificação Decimal de Dewey - CDD.

No presente trabalho, busca-se examinar a representação da religião brasileira Umbanda no sistema de classificação CDD. Visa-se apresentar um breve esboço a partir da percepção de representação no âmbito das representações sociais pelo discurso dos praticantes da religião no Brasil com a utilização da Teoria das Representações Sociais.

\section{Sub-representação do Negro no Brasil}

No Brasil, a expressão "negro" é um termo polissêmico que se refere ao homem ou à mulher de pele negra, de pigmentação de pele mais escura, aspecto que estabelece a um só tempo, na sociedade brasileira, dois ou mais significados distintos. Por um lado, define uma categoria étnico-racial, a raça negra, grupo majoritário da população brasileira, que é constantemente alvo de discriminação. Por outro lado, adquire contorno pejorativo, por exemplo, sujo, encardido, maldito, melancólico, funesto, perverso (Ferreira, 2004, p.1393). Isso se reflete diretamente na dificuldade de se entender e apresentar definições mais concisas do termo e sua utilização nos lugares, espaços da realidade (Munanga, 2004):

Parece simples definir quem é negro no Brasil. Mas, num país que desenvolveu o desejo de branqueamento, não é fácil apresentar uma definição de quem é negro ou não. Há pessoas negras que introjetaram o ideal de branqueamento e não se consideram como negras. Assim, a questão da identidade do negro é um processo doloroso. Os conceitos de negro e de branco têm um fundamento etnosemântico, político e ideológico, mas não um conteúdo biológico. Politicamente, os que atuam nos movimentos negros organizados qualificam como negra qualquer pessoa que tenha essa aparência. É uma qualificação política que se aproxima da definição norte-americana.

As interações entre o indivíduo negro e a sociedade ocorrem de maneira enviesada por termos potencialmente balizadores do discurso de rejeição e desconstrução das identidades. Escolher um termo em detrimento de outro para representar o conhecimento e informações sobre indivíduos e grupos é uma tarefa complexa com riscos de sub-representações de certos segmentos sociais.

Nesse entendimento, a elaboração de instrumentos de classificação do conhecimento como estruturas hierárquicas que estabelecem categorias de conceitos superiores a outros, exige, por parte dos profissionais da informação, perceber a dinâmica social na produção e os contextos de produção desses termos, bem como suas variáveis para representação e reconhecimento pelos grupos representados.

As críticas justificam-se pela presença de uma espécie de ideologia da neutralidade sobre a elaboração de sistemas de representação do conhecimento, circunscritas à objetividade e "neutralidade" sempre requisitadas como práticas eficientes para a construção de sistema de organização do conhecimento (Hjørland, 2007, p.8). As representações podem configurar a ausência de dialética e privilegiar um ponto de vista do poder que viabiliza o processo e se consolida na ocultação dos discursos de outras comunidades discursivas como indígenas, negros, mulheres, LGBT Lésbicas, Gays, Bissexuais, Transexuais, dentre outros.

No âmbito desta pesquisa, o que está em evidência na denominada comunidade discursiva, vincula-se à consolidação e valorização da cultura e da identidade dos povos afrodescendentes no contexto brasileiro. Ademais, não se trata apenas da precisão da escolha sobre termos que representem conceitos, mas, sobretudo, evitar a ausência daqueles que possam minimizar ou, praticamente, excluir grupos históricos: "Desta forma, as palavras podem tornar invisíveis grupos inteiros ou algumas características desses grupos" (Azais, 2005, p.8, Tradução nossa).

Como se sabe, em quatro séculos, o Brasil tem negligenciado o acesso, incorporação social e política da população negra. O país com o maior contingente de negros fora do continente africano perpetuou uma lógica de branqueamento dos espaços e consequente negação dos referenciais das populações afrodescendentes brasileiras. $O$ capítulo mais vexatório da história brasileira, a escravidão, teve impacto decisivo na formação social brasileira. As populações negras estavam ocultas do fazer histórico, o que passa a mudar a partir do momento de rebelião na Colônia com a edificação dos quilombos. Esse novo espaço de ocupação negra, antagônico ao outro (senzala) propôs o protagonismo negro (Freitas, 2004).

Em todas as instâncias, em âmbito público e privado, a maioria da população negra brasileira tem sido alijada dos espaços de decisão na política, economia, cultura, educação. Essa realidade sobre a população afrodescendente materializa-se em dados como os da última eleição para o congresso brasileiro, em que apenas $22 \%$ dos eleitos se declararam negros ou pardos (Brasil, 2016). Na educação superior, por exemplo, mesmo com a implementação das cotas raciais e programas de governo marcados por ações afirmativas, fruto de muita luta do movimento negro, essa população, no âmbito das universidades, 
ainda é numericamente inferior em relação aos brancos. Segundo o IBGE (2016)(2), a participação de jovens com idade universitária entre a população negra no ano de 2015 , correspondia a $12,8 \%$. Se comparada com a população branca na mesma faixa etária, os brancos representavam $26,5 \%$.

Além disso, a presença de docentes negros nas universidades brasileiras é um problema visível. Por exemplo, o censo da Universidade de São Paulo(3) de 2015, revelou que, no seu quadro de docentes, apenas $1,83 \%$ dos professores são negros e $94,6 \%$ são brancos. Desse modo, tem se perpetuado, em um só movimento, as condições de exclusão na sociedade brasileira e sustentação do ambiente propício ao racismo. Por outra via, essas informações podem ser catalisadoras de energias e provocar o pesquisador para analisar e entender a sistêmica exclusão das comunidades, bem como proporcionar elementos reflexivos para o fortalecimento da identidade afrodescendente. Narrativas consideradas conservadoras figuram como pilares de uma realidade de valores simbólicos da branquitude nas representações que devem ser quebradas por novas configurações da realidade do negro brasileiro e constituir outra dinâmica nas representações do conhecimento desses grupos.

As representações são ações que atribuem sentidos ou significados sobre aspectos que representam o cotidiano. Para Ferreira (2004), a representação pode ser uma "coisa que se representa" e, em outra acepção, pode ser a "reprodução daquilo que se pensa". No contexto da teoria dos signos de Charles S. Peirce, representar é "estar em lugar de, isto é, estar numa tal relação com outro que, para certos propósitos, é compreendido por alguma mente como se fosse a outra coisa" (Peirce, 1977, p.61). No caso, a dinâmica sociocultural, um jogo de poder implementa representações determinadas mediante forças políticas e econômicas que produzem, obviamente, distorções, inclinações e dissimulam a presença e contribuição de grupos excluídos socialmente.

No Brasil, entre as décadas de 1930 até 1970, antropólogos e sociólogos contribuíram com pesquisas compostas de narrativas que sugeriram o padrão de nação com vistas ao povo ideal, miscigenado, rumo ao status de nação civilizada. Destacam-se ideias concebidas sob noções de raça superior, culturas superiores, civilidade, progresso e intermitentemente interligadas ao contexto europeu sempre presentes na linguagem racista brasileira (Serra; Schucman, 2012). A representação do conhecimento afrodescendente insere-se na perspectiva de luta e resistência para a manutenção da cultura e identidade da população negra no Brasil.
Desenvolver sistemas para organizar o conhecimento está na base da formação da ciência e, de modo mais preciso, no que concerne à Organização do Conhecimento, o centro de suas preocupações. Para tanto, buscar resolver problemas de representação do conhecimento é fundamental e exige compreender os fenômenos reais, reunir conceitos e elaborar processos para representar e proporcionar o acesso ao conhecimento produzido por comunidades discursivas.

A atividade de representação do conhecimento de comunidades ou grupos tradicionais, em favor do acesso ao conhecimento, deve ser pautado por uma leitura plural da realidade, o que nem sempre foi o caso para a situação do negro no Brasil. Acreditamos que os instrumentos de organização do conhecimento utilizados com frequência em bibliotecas no Brasil ainda não representam adequadamente a figura do negro e suas características culturais e religiosas, em especial, a Classificação Decimal de Dewey. Ademais, tais sistemas não promovem o conhecimento da estrutura conceitual própria da cultura negra e de suas religiões, suas especificidades e seu papel na história do Brasil em sua dinâmica de representar esta realidade.

\section{Representações Sociais e CDD: representação da Umbanda}

Os contornos iniciais sobre a Teoria das Representações Sociais são creditados a Émile Durkheim por defender uma dimensão específica chamada "representação coletiva". Em sua acepção, dissocia-se da representação do pensamento individual em que Durkheim distingue as representações sociais coletivas como um ramo de estudo da Sociologia e o das representações individuais que ficava a cargo da Psicologia (Farr, 1995, p.35). Em linhas gerais, Durkheim acreditava que os padrões que ajudavam a explicar a realidade, os fenômenos construídos socialmente na representação coletiva, não teriam como utilizar o mesmo padrão para explicar os fenômenos individuais. Na concepção abordada por Durkheim, o indivíduo é influenciado pela sociedade responsável por representar o sentimento individual. Nessa acepção da representação, o contexto sugere uma representação "sobre" as compreensões e sentimentos universais da sociedade e submete o individual a essas regras de representação de modo impositivo. Serge Moscovici (1978, p.26), no âmbito da Teoria da Representação Social, considera que o individual é parte constituinte do contexto das representações sociais como uma "modalidade de conhecimento que tem por função a elaboração de comportamentos e a comunicação entre indi- 
víduos". Essa abordagem teórica deve ser utilizada para entrever os meandros da representação do conhecimento e, como tais, funcionam e operam para sub-representar conteúdos das comunidades negras no Brasil, como é o caso do conhecimento religioso.

Assim, buscou-se identificar, de acordo com o propósito da pesquisa, como a representação das religiões de influência da cultura africana, por exemplo, são apresentadas no contexto da CDD. Em outras abordagens, como de Afolabi (1992) sobre a representação do protestantismo na CDD, a comparação entre conceitos (Rizzi, 2007; 2008) com viés crítico é recorrente em análises que indicam possíveis desvios e/ou sub-representações ocasionados pelo ponto de vista da realidade representada em sistemas universais de representação do conhecimento humano como a CDD.

Desse modo, no levantamento realizado, encontramos na edição CDD22 e CDD23 registros sobre religiões de influência africana. A classe 200 - Religião na CDD é majoritariamente dominada por religiões cristãs. Ao comparar as religiões de matriz africana com outras, segundo Miranda (2007; 2009), ainda assim entre as classes 210 e 290, deixam de ser feitas menções das expressões de fé de influência africana. Apenas a partir da classe 299.6, veremos notações específicas, mas se observa que a posição hierárquica indica que essas expressões de fé estão em condição de inferioridade se comparadas a outras. $\mathrm{Na}$ CDD23 algumas notações foram encontradas para o tema Black. Por exemplo, sobre religiões há relação direta com público negro (Black) em notações específicas dos Estados Unidos da América:

287.8 Black Methodist churches of United States origens

299.6 Religions Originating among of United States origins.

\section{Other religions}

299 Religions not provided for elsewhere

$\mathrm{Na}$ CDD22/2003, a classe 299.6 Religions originating among Black Africans and people os Black African descent acolhe em seu núcleo as religiões de origem e relação de descendência cultural africana. Mais adiante, em 299.67 Specific religions trata desse arranjo que visa a agrupar religiões e movimentos que expressam a fé de matriz africana.

Entretanto, segundo análise realizada em Miranda (2007), essas classes delimitam os relacionamentos possíveis e revelam relativa incompreensão e "dispersão semântica" face às incon- sistências que impactariam no momento da recuperação. Em nossa perspectiva, muito antes de pensar na recuperação, essa dimensão possibilita verificar o quão distante é estruturar a diversidade cultural na prática desses sistemas. Ademais, a utilização de sistemas universalistas de categorização do conhecimento, permite-nos inferir que sua utilização deve ser respaldada por máxima atenção, pois lida com contextos complexos de produção do conhecimento.

Tendo em vista a necessária e adequada nomeação das classes, corroboramos com a pesquisa de Miranda (2007), que constatou um padrão que, em primeira análise, denota um posicionamento demarcado face a essas matrizes religiosas, ocultamento e distanciamento desses grupos no ato de organizar e representar o conhecimento.

No tocante às edições CDD22 e na CDD23, manteve-se o padrão no que se refere ao fato de alocar essas matrizes religiosas em condição inferiorizada no sistema:

\subsection{Umbanda}

299.673 Candomblé

299.674 Santeria

\subsection{Voodoo}

\subsection{Rastafari Movement}

No que se refere às religiões de matriz africana, principalmente Umbanda(4) e Candomblé(5) no cenário brasileiro, esse tipo de sub-representação incide diretamente na questão das identidades dos grupos que professam esse tipo de expressão de fé. Muito embora saibamos que essas classificações foram criadas para atender demandas específicas das regiões nas quais foram desenvolvidas, com forte tendência cristã, já indicada na classe 200 , a adoção em contextos que diferem daquele, deve supor certo cuidado na hora de estabelecer as notações e os arranjos na disposição dos materiais nos acervos.

No caso ,a Umbanda, por exemplo, é uma religião criada entre o fim do século XIX e início do século XX no Brasil. Caracteriza-se pela confluência de ritos na origem, influenciados por outras expressões religiosas como espiritismo, catolicismo, cerimônias religiosas indígenas, ritos africanos do Candomblé que formam a base na composição dos elementos complexos dessa religião que reúne descendentes africanos e outros grupos sociais.

Ao se questionar um Umbandista (membro praticante da Umbanda) sobre sua religião e a percepção coletiva, notamos o grau de insuficiência representativa desses sistemas para representar 
a complexidade desse tipo de religião. Em muitos casos, afastam-se completamente da realidade dos grupos representados.

A religião é estruturada a partir de suas linhas, isto é, recebe influências de matrizes como Africanismo, Kardecismo, Cristianismo dentre outras. A existência dessas linhas inviabiliza a menção da Umbanda apenas na seção correspondente às religiões africanas. Essas linhas correspondem a correntes vibratórias ligadas a uma entidade divina, um Orixá. Segundo Barbosa Júnior (2014, p.218) essas linhas, mais conhecidas ou que se manifestam em seus rituais com maior frequência nos centros de Umbanda, variam de acordo com as influências regionais, a saber:

$$
\begin{aligned}
& 1^{\mathrm{a}} \text { linha: Oxalá } \\
& 2^{\mathrm{a}} \text { linha: lemanjá } \\
& 3^{\mathrm{a}} \text { linha: Xangô } \\
& 4^{\mathrm{a}} \text { linha: Ogum } \\
& 5^{\mathrm{a}} \text { linha: Oxóssi } \\
& 6^{\mathrm{a}} \text { linha: Yori } \\
& 7^{\mathrm{a}} \text { linha: Yorimá }
\end{aligned}
$$

A Umbanda, do ponto de vista de suas práticas, possui duas dimensões classificadas de dois modos: Direita e Esquerda. A primeira composta pelos Orixás e espíritos chamados de Caboclos e Pretos Velhos que trabalham nas casas ou terreiros (locais ritualísticos). A segunda, trabalhada com entidades espirituais também desencarnadas denominadas Exus e Pombas Giras, por exemplo.

Diante do exposto, percebemos que os sistemas universais, no caso em questão a CDD, distanciam-se muito em sua representação adotada para abordar a complexidade da Umbanda, apresentada neste artigo.

Ao descrever a Umbanda, como tem sido cotidianamente representada, os praticantes da mesma reconhecem que o contexto social brasileiro (senso comum) a tem rotulada como "seita demoníaca", "feitiçaria", "macumba", "Xangô" (Orixá), "maligna", "do inferno".

Essas representações coletivo-sociais de caráter moral têm ocasionado aos grupos a estigmatização via interpretações equivocadas sobre os rituais e segmentos da Umbanda. A repetição desses termos, principalmente por grupos vinculados a outros segmentos religiosos, como grupos neopentecostais, por exemplo, tem imputado aos indivíduos atributos incompatíveis com as práticas sugeridas por esses grupos. Esse fato pode incidir em novas representações pelos sistemas de organização do conhecimento, reforçando o ciclo de preconceito em detrimento do esclarecimento público do tema. Essas representações adquirem valor simbólico nessas expressões, estrategicamente forjadas para "fins políticos e sociais" (Jodelet, 2001, p.20).

Dessas operações interpretativas, emergem do coletivo via simbólico, ações degenerativas sobre determinado grupo social que reforçam comportamentos violentos, estruturam as condutas face à exposição simbólica negativa sobre os praticantes da Umbanda, principalmente, relacionadas a sua indumentária, músicas acompanhados por toque de instrumentos percussivos que recebem a inadequada conotação demoníaca. Inclusive, registram-se violentas ações de destruição de templos e perseguições aos adeptos dessa religião brasileira.

As escolhas terminológicas na representação, a partir da representação social, deve se inserir no contexto para extração dos termos utilizados pelos grupos. No cenário em questão, isso é acentuado pelas representações preconceituosas presentes na realidade brasileira referente à Umbanda.

\section{Considerações finais}

Os sistemas universais utilizados no Brasil, como a CDD, ao que consta até o presente momento, não nos parecem adequados quando confrontados com a questão da representação do negro, mais precisamente no que se refere às religiões de matriz africana como a Umbanda, principalmente ao se observar o contexto da diversidade cultural brasileira. A não representação dos não brancos reforça narrativas e discursos na sociedade brasileira promotoras de desigualdades sociais. Para tanto, ao propor organizar o conhecimento produzido por esses grupos, deverá se levar em conta aspectos que envolvam economia, política, cultura, religião, educação dos grupos e extair da realidade dos povos afrodescendentes os elementos que comporão a representação submetida ao crivo do grupo. Nesse sentido, a Teoria das Representações Sociais subsidiará a abordagem do espaço social e dos problemas que afetam sensivelmente aspectos identitários dos povos afrodescendentes brasileiros.

\section{Notas}

(1) https://nacoesunidas.org/tema/lgbt/

(2) O Instituto Brasileiro de Geografia e Estatística - IBGE, tem a missão de retratar a realidade brasileira sobre vários aspectos com a produção de informações para subsidiar a sociedade civil e órgãos de governo de todas as esferas. Para tanto, realiza inúmeras pesquisas como, por exemplo, o censo demográfico, agropecuário, Pesquisa Nacional por Amostra Domiciliar - PNAD. Mais informações em: www.ibge.gov.br. 
(3) http://jornal.usp.br/atualidades/a-presenca-invisivel-do-negro-na-universidade/

(4) A Umbanda é uma religião afro-brasileira, que sincretiza o catolicismo, espiritismo e as religiosidades africana, indiana e indígena. É uma religião criada no Rio de Janeiro há mais de cem anos. Mais informações: http://www.fietreca.org.br/umbanda-sagrada/ e http://umbanda-orixas.info/o-que-e-umbanda.html.

5) O Candomblé tem origem banta africana trazida ao Brasil pelos escravos oriundos da África. Mais informações: http://www.afreaka.com.br/notas/candomble-origem-significado-e-funcionamento/

\section{Referencias}

Afolabi, Michael (1992). Spiritual Matters: Provision for Independent African Churches in General Classification Schemes. // International Classification. 19:4, 210-213.

Azais, H. I. (2005). Lenguaje y discriminación. México: Consejo Nacional para Previnir la Descriminación.

Barbosa Júnior, A. (2014). O Livro essencial de Umbanda. São Paulo: Universo dos Livros.

Barité, M. (2013). Diccionário de Organización del Conocimiento-Clasificación, Indización, Terminología. Montivideo: Prodic,.

Brasil. (2016). Tribunal Superior Eleitoral. DivulgaCandContas. Divulgação das candidaturas registradas no Brasil das eleições 2016. Brasília.

Dewey, m. (2011). Dewey decimal classification and relative index. 23st ed. Albany: Forest Press, 4 v.

Dewey, M. (2003). Dewey decimal classification and relative index. 22st ed. Albany: Forest Press, $4 \mathrm{v}$.

Ferreira, A. B. de. H. (2004). Novo dicionário de língua portuguesa. 3. ed. Curitiba: Positivo.

Freitas, D. (2004). República de Palmares-pesquisa e comentários em documentos históricos do Século XVII. Maceió: Edufal; Ideário.

Farr, R. M. (1995). Representações sociais: a teoria e sua história. // Guareschl, P. A.; Jovchelovitch, S. (Org.). Textos em representações sociais. 3. ed. Petrópolis: Vozes. 31-59.

Hall, S. A. (2001) Identidade cultural na pós-modernidade. 5 ed. Rio de Janeiro: DP\&A.
Hjørland, B. (2007). Arguments for 'The Bibliographical Paradigm'. Some Thoughts Inspired by the New English Edition of the UDC.// Information Research, 12:4, 2007.

lbge. (2016). Síntese de indicadores sociais: uma análise das condições de vida da população brasileira. Brasília-DF: IBGE, 2016.

Jodelet, D. (Org.).(2001). As representações sociais. Rio de Janeiro: EdUERJ, 2001.

Miranda, M. L. C. (2009) A organização do etnoconhecimento: a representação do conhecimento afrodescendente em religião na CDD. // Revista África e africanidades. Rio de Janeiro. 1:4.

Miranda, M. L. C. (2007). A organização do etnoconhecimento: a representação do conhecimento afrodescendente em Religião na CDD.. In: Encontro Nacional de Pesquisa em Ciência da Informação, 2007, Anais... Salvador. VIII ENANCIB.

Moscovici, S.(2003). Representações Sociais: investigação em psicologia social. Petrópolis, RJ: Vozes, 2003. 1-100.

Moscovici, S. (1978). A representação social da psicanálise. Rio de Janeiro: Zahar.

Munanga, K. (2004). A difícil tarefa de definir quem é negro no Brasil. // Estudos Avançados. São Paulo, 18:50, 5166.

Peirce, C. S. (1977). Semiótica. São Paulo: Perspectiva.

Rizzi, I. R. F. (2008). A paz nos instrumentos de Organização da Informação - uma análise dos conceitos de paz e guerra, da Cultura de Paz e dos Estudos para Paz na Classificação Decimal de Dewey. Dissertação Mestrado, Faculdade de Filosofia e Ciências, Universidade Estadual Paulista, Marília, São Paulo, Brasil.

Rizzi, I. R. F. (2007). A Classificação Decimal de Dewey e a Cultura de Paz. Anais do Encontro Nacional Nacional de Pesquisa em Ciência da Informação. Salvador, BA, Brasil, 8.

Santos, B. S. (1999). Pela mão de Alice: o social e o político na pós-modernidade. 7.ed. Porto: Afrontamento.

Serra, L. N.; Schucman, L. V. (2012). Branquitude e progresso: a Liga Paulista de Higiene Mental e dos discursos paulistanos na contemporaneidade. // Estudos e Pesquisas em Psicologia. Rio de Janeiro. 12:1.

Enviado: 2018-03-31. Segunda versión: 2018-06-25. Aceptado: 2018-09-05 